\title{
Studies on Functionalization of Apple Waste for Heavy Metal Treatment
}

\author{
Puspa Lal Homagai, Deepak Bashyal, Hari Poudyal and Kedar Nath Ghimire \\ Central Department of Chemistry, Tribhuvan University., Kirtipur, Kathmandu, Nepal \\ e-email.homagaipl@gmail.com
}

\begin{abstract}
The present investigation is to investigate the potential and effectiveness of two types of biosorbents as cation exchanger, functionalized with carboxylic acid and xanthated groups onto apple waste. Both the adsorbent materials exhibited highly selective behavior for heavy metal treatment and followed Langmuir adsorption isotherm model. The maximum adsorption capacity evaluated for iron, cadmium, zinc and lead onto them have shown their potential ability in the treatment of heavy metals from aqueous medium. Dominant sorption mechanisms are revealed to be ionexchange process.
\end{abstract}

Key words: adsorption, biopolymer, ion exchange, saponification, xanthation

\section{Introduction}

Metal ions produced in appreciable amount and released during industrial activities pose a serious threat to the environment and are harmful to aquatic life and human health. A wide range of physical and chemical processes are available for the removal of toxic heavy metals from contaminated water, such as electro-chemical precipitation, ultra-filtration, ion exchange, reverse osmosis and adsorption using commercial activated carbon (APHA 1998). However, these are not economically appealing because of technical viability and high operational cost.

The utilization of agricultural by-products for removal of heavy metals from aqueous solutions is getting much concern these days. Natural biopolymers are industrially attractive because of their capability of lowering transition metal-ion concentration to parts per billion concentrations and may have potential to be used as low cost adsorbents, as they represent unused resources, widely available and are environmentally friendly (Ghimire et al. 2003). In Nepal, apple is a most abundant fruit available at any season in the market. The residue generated as waste during juicing at the juice centers is easily available as feed material. The exchange/ sorption properties of apple waste are mainly due to the presence of some functional groups, such as carboxylic and hydroxyl, which have a high affinity for metal ions
(Ghimire et al. 2008). In recent years, development of surface modified biowaste material has generated a diversity of adsorbents with far superior adsorption capacity (Biswas et al. 2007). The use of apple waste with surface modification to improve its metal removal performance would add its economic value and most importantly, provide a potentially inexpensive alternative to existing commercial activated carbon (Mohan et al. 2007). The present investigation was carried out regarding the adsorptive behavior of saponificated and xanthated apple wastes. Under such circumstances, we have optimized the saponification process in order to create a suitable chelating group, carboxylic functionality and at present, the xanthate group onto polymeric analog contained in apple wastes. This study is to explore the biosorbent of two different functionalized materials and to compare the results in terms of maximum adsorption capacity for heavy metals such as lead, cadmium, zinc and iron, and elucidate the mechanisms of heavy metal adsorption onto them.

\section{Materials and methods \\ Preparation of adsorbent gel}

Prior to the adsorption tests, the dried raw apple waste was treated with $18 \%$ sodium hydroxide and shaked for $1 \mathrm{~h}$ then $10 \mathrm{ml}$ of carbon disulphide was added and 
the mixture was stirred in rotary shaker at $25^{\circ} \mathrm{C}$ for $24 \mathrm{~h}$. The obtained products (hereafter called xanthated apple waste-XAW) were washed with water until the $\mathrm{pH}$ was neutral and dried for $24 \mathrm{~h}$, cooled at room temperature, and stored in a desiccator until use. Similarly, $100 \mathrm{~g}$ wet apple waste was treated with $0.2 \mathrm{M}$ calcium hydroxide and equilibrated for $24 \mathrm{~h}$ using a mechanical shaker. The mixture was washed until neutral $\mathrm{pH}$ and then dried at $70{ }^{\circ} \mathrm{C}$ and finally kept in a desiccator. The material prepared in this way was abbreviated as saponificated apple waste (SAW). The maximum number of exchangeable functional sites on the adsorbent was determined through adsorption and subsequent acidbase titration. For the determination, $50 \mathrm{mg}$ of dried $\mathrm{H}^{+}$form gel and $50 \mathrm{ml}$ of $0.01 \mathrm{M}$ of sodium hydroxide solution were equilibrated for $24 \mathrm{~h}$ at $25^{\circ} \mathrm{C}$. The decrease in basicity in the filtrate was evaluated by titrating the filtrate with $0.01 \mathrm{M}$ hydrochloric acid using phenolphthalein as an indicator.

Batch experiments were carried out with synthetic solution of predetermined concentration of lead, cadmium, zinc and iron at $25^{\circ} \mathrm{C}$ with $20 \mathrm{ml}$ of solution and $20 \mathrm{mg}$ of sorbent at $120 \mathrm{rpm}$ in a rotary shaker for 24 hours. For $\mathrm{pH}$ studies initial metal ion concentration of $50 \mathrm{mg} / \mathrm{l}$, for isotherm studies $10-500 \mathrm{mg} / \mathrm{l}$ of each metal were taken (Dakal et al. 2005). Concentration of the metal solution was assessed using flame atomic absorption (AA) spectrometer (Perkin Elmer model AAnalyst 100).

The adsorption efficiency $\mathrm{A} \%$, and sorption capacity $\mathrm{q}_{\mathrm{e}}$ of metal ion was calculated by using equations 1 and 2 respectively.

$$
\begin{aligned}
& \mathbf{A} \%=\frac{\mathbf{C}_{\mathrm{i}}-\mathbf{C}_{\mathrm{e}}}{\mathbf{C}_{\mathrm{i}}} \times 100 \\
& \mathbf{q}_{\mathrm{e}}=\frac{\mathbf{C}_{\mathrm{i}}-\mathbf{C}_{\mathrm{e}}}{\mathbf{w} \times 1000} \times \mathrm{V}
\end{aligned}
$$

where, $q_{e}$ represents the amount of metal uptaken per unit mass of adsorbent $(\mathrm{mg} / \mathrm{g})$ at equilibrium time, $\mathrm{V}$ is the volume of test solution (ml), $\mathrm{W}$ is the mass of dry adsorbent $(\mathrm{g}), \mathrm{C}_{\mathrm{i}}$ and $\mathrm{C}_{\mathrm{e}}$ are the concentrations of metal solution in $\mathrm{mg} / \mathrm{l}$ at initially and at equilibrium time, respectively.

\section{Results and Discussion}

\section{Evaluation of maximum exchangeable cation}

The maximum amount of exchangeable cation contained in $\mathrm{H}^{+}$-form xanthated and saponifcated gel was evaluated as $2.52 \mathrm{~mol} / \mathrm{kg}$ and $2.65 \mathrm{~mol} / \mathrm{kg}$ respectively. It revealed that both of the prepared adsorbents showed higher number of ion exchangeable sites, which could perform maximum amount of metal ion sequestering ability.

\section{Effect of contact time}

The results of time dependency experiments conducted for the binding of $\mathrm{Pb}$ (II), $\mathrm{Cd}$ (II), $\mathrm{Zn}$ (II) and $\mathrm{Fe}$ (III) ions onto xantahted and saponificated apple are shown on Figure 1. The overall sorption behavior of $\mathrm{Pb}(\mathrm{II})$, $\mathrm{Cd}(\mathrm{II}), \mathrm{Zn}(\mathrm{II})$ and $\mathrm{Fe}$ (III) onto both of the adsorbent was similar with differences in amounts adsorbed. The equilibrium time of all metal ions was above $10 \mathrm{~h}$ and was found nearly similar for both XAW and SAW.

\section{Effect of $\mathrm{pH}$ on the adsorption of metal ions}

$\mathrm{pH}$ is an important parameter for adsorption of metal ions from aqueous solution because it affects the solubility of the metal ions, concentration of the counter ions on the functional groups of the adsorbent and the degree of ionization of the adsorbate during adsorption (Pavasant et al. 2006). To examine the effect of $\mathrm{pH}$ on the $\mathrm{Pb}(\mathrm{II}), \mathrm{Cd}$ (II), $\mathrm{Zn}$ (II) and $\mathrm{Fe}(\mathrm{III})$ removal efficiency, the $\mathrm{pH}$ varied from 1.0 to 8.0. As shown in Fig. 2, the uptake of free ionic metals depends on $\mathrm{pH}$, where optimal metal removal efficiency occurs at $\mathrm{pH} 3,4,5$ and 6 for $\mathrm{Pb}(\mathrm{II}), \mathrm{Cd}(\mathrm{II}), \mathrm{Zn}(\mathrm{II})$ and $\mathrm{Fe}(\mathrm{III})$ respectively on $\mathrm{XAW}$ and then declining at higher $\mathrm{pH}$ due to solubility of many metal ions in solution decreases enough for precipitation to occur with increasing $\mathrm{pH}$. This suggests that, the metal ions are adsorbed according to a cation exchange mechanism. Removal efficiency for each metal increased from $65 \%$ to $92 \%$ over the optimum $\mathrm{pH}$ range. The SAW as an adsorbent also showed similar trends with the same removal efficiency and slight different optimum $\mathrm{pH}$ value. 


\section{Maximum adsorption capacity}

Figure 2 shows the plot of adsorption isotherm for $\mathrm{Pb}(\mathrm{II})$, $\mathrm{Cd}(\mathrm{II}), \mathrm{Zn}(\mathrm{II})$ and $\mathrm{Fe}(\mathrm{III})$ on the XAW and SAW respectively. It appears that the adsorption of the metal ions increases with the increase in equilibrium metal ion concentration.

Uptake is eventually limited by the fixed number of active sites and resulting plateau of isotherm, suggesting that metal ions are adsorbed onto the gel according to the Langmuir type adsorption. From Figure 3 the results obtained are furnished in Table 1.

The maximum adsorption capacity of XAW as an adsorbent were evaluated as 250,192.30, 123.45 and $62.89 \mathrm{mg} / \mathrm{g}$ for $\mathrm{Pb}(\mathrm{II}), \mathrm{Cd}(\mathrm{II}), \mathrm{Zn}(\mathrm{II})$ and $\mathrm{Fe}(\mathrm{III})$, respectively. Similar types of results were obtained for SAW also and are depicted in Table 1. Such high adsorption capacities of both the adsorbents for typical toxic heavy metal ions are noteworthy together with the higher selectivity and expected to be employed in commercial process for the recovery of heavy metal ions from contaminated waste water (Reddad et al. 2002).

\section{Metal adsorption}

Because the natural apple waste contains polysaccharides such as cellulose along with pectin containing a number of hydroxyl and carboxyl surface functional groups. In fact the unique mixture of polysaccharide, mainly cellulose and pectin is largely supposed to be responsible for xanthation as well as saponification which in turn possess excellent metal sequestering ability by creating exchangeable cation sites. Metal adsorption efficiency has to be related to the total number of surface functional groups available onto the adsorbent. As the adsorption behavior of modified adsorbent is predominantly $\mathrm{pH}$ dependent, the probable mechanism between metal ions-adsorbent under study would be ion-exchange and/or specific chemical adsorption.

Table 1. Langmuir biosorption isotherm parameter and correlation coefficient for adsorption of metal ions onto XAW and SAW with experimental $\mathrm{q}_{\max }$

\begin{tabular}{l|c|l|l|l|l|l|l|c}
\hline Metal ions & \multicolumn{3}{|c|}{ Xanthated apple waste } & \multicolumn{3}{c}{ Saponifcated apple waste } & \\
& $\mathrm{q}_{\max }(\mathrm{mg} / \mathrm{g})$ & $\mathrm{b}(\mathrm{I} / \mathrm{mg})$ & $\mathrm{R}^{2}$ & $\begin{array}{l}\text { Experimental } \\
\mathrm{q}_{\max }(\mathrm{mg} / \mathrm{g})\end{array}$ & $\mathrm{q}_{\max }(\mathrm{mg} / \mathrm{g})$ & $\mathrm{b}(\mathrm{I} / \mathrm{mg})$ & $\mathrm{R}^{2}$ & $\begin{array}{l}\text { Experimental } \\
\mathrm{q}_{\max }(\mathrm{mg} / \mathrm{g})\end{array}$ \\
\hline $\mathrm{Pb}(\mathrm{II})$ & 250.00 & 0.064 & 0.994 & 240 & 256.4 & 0.11 & 0.993 & 237 \\
$\mathrm{Cd}(\mathrm{II})$ & 192.30 & 0.064 & 0.984 & 180 & 196 & 0.07 & 0.993 & 190 \\
$\mathrm{Zn}(\mathrm{II})$ & 123.45 & 0.040 & 0.985 & 120 & 62.5 & 0.12 & 0.995 & 60 \\
$\mathrm{e}(\mathrm{III})$ & 62.89 & 0.032 & 0.997 & 58 & 144.9 & 0.06 & 0.990 & 147 \\
\hline
\end{tabular}

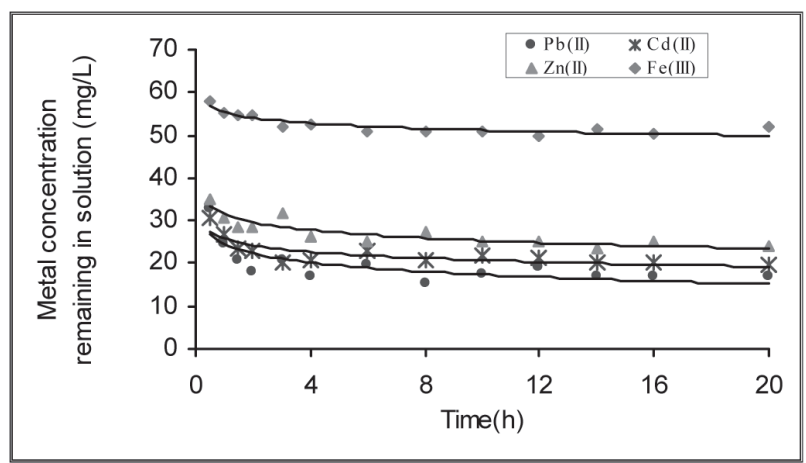

(a)

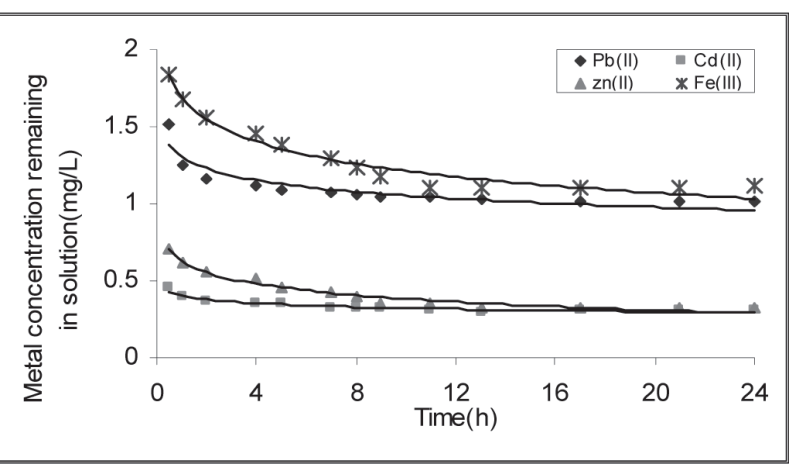

(b)

Fig. 1. Contact time study for heavy metals adsorption onto (a) XAW at initial concentration of $50 \mathrm{mg} / \mathrm{l}$ and (b) SAW at initial concentration of $10 \mathrm{mg} / 1$ 


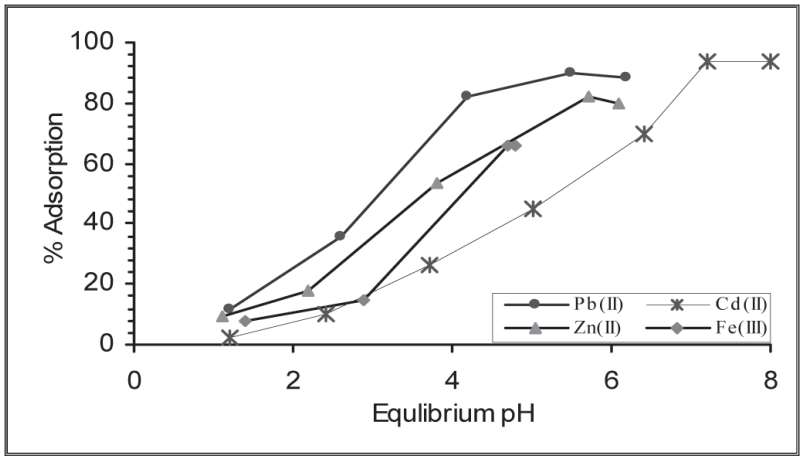

(a)

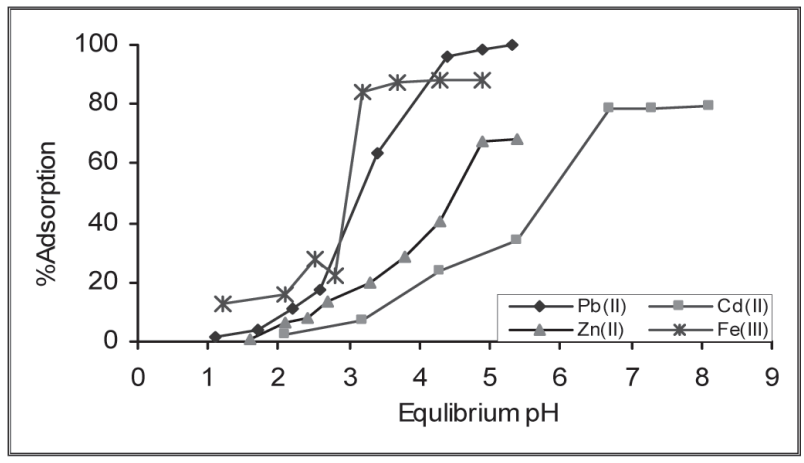

(b)

Fig. 2. Effect of $\mathrm{pH}$ on adsorption of several metal ions onto (a) xanthated and (b) saponificated apple waste at $25^{\circ} \mathrm{C}$

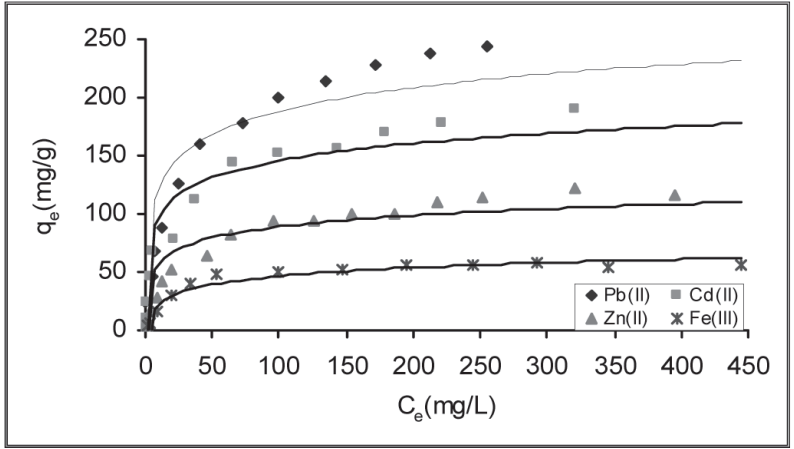

(a)

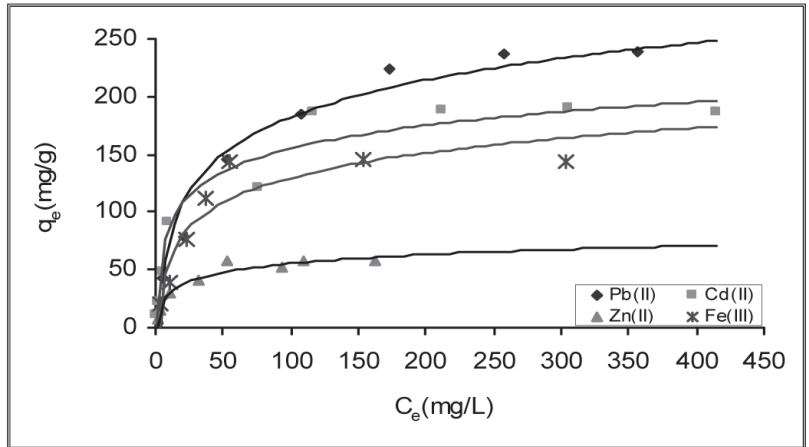

(b)

Fig. 3. (a) The adsorption isotherm of some metal ions onto (a) XAW and (b) SAW at optimum pH
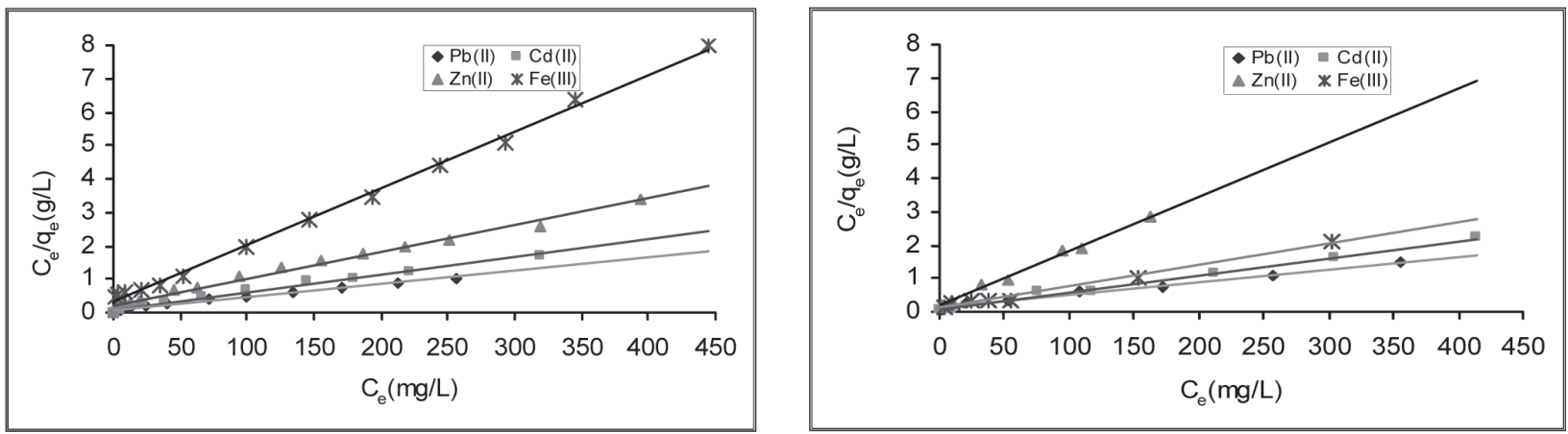

Fig. 4. Langmuir plot for the adsorption of metal ions onto (a) XAW and (b) SAW at $25^{\circ} \mathrm{C}$. The straight line is the regression line obtained by least square fit method 

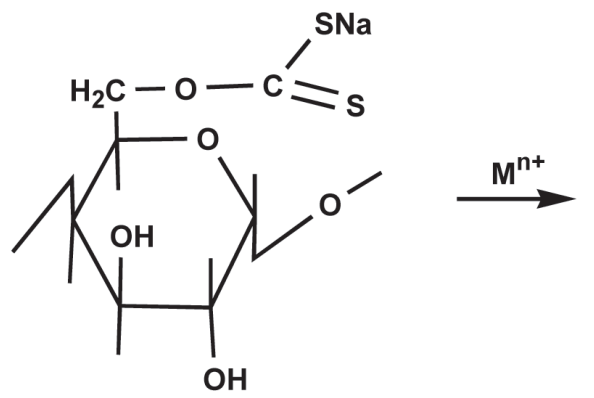

(a)
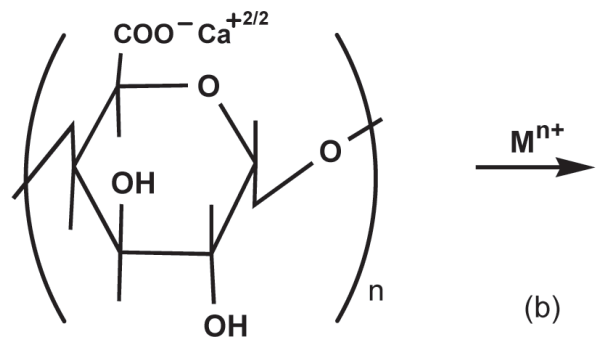

(b)
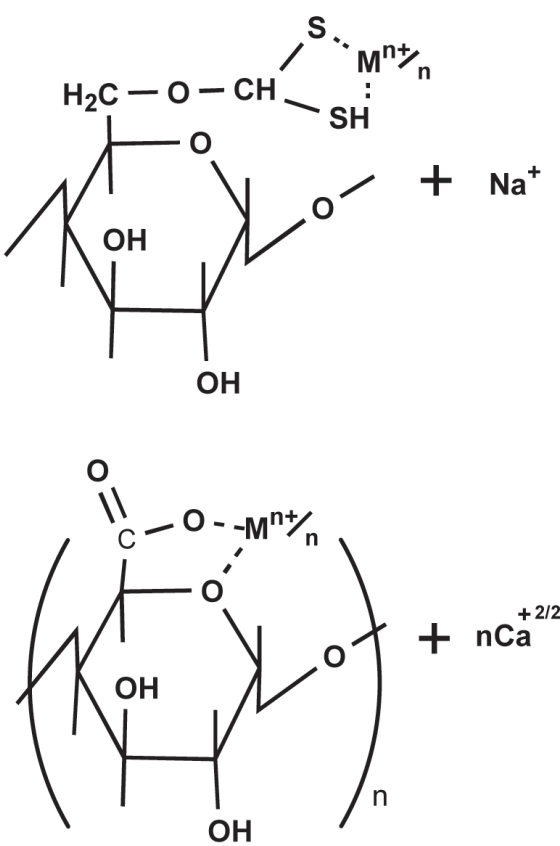

Fig. 5. Mechanism of adsorption of metal ions onto (a) XAW and (b) SAW

\section{Conclusion}

Our present study showed that chemical modification onto apple waste viz., XAW and SAW for the removal of $\mathrm{Pb}(\mathrm{II}), \mathrm{Cd}(\mathrm{II}), \mathrm{Zn}$ (II) and $\mathrm{Fe}$ (III) appeared to be technically feasible, eco-friendly with high efficacy. The uptake of metal ions was dependent on $\mathrm{pH}$ of the medium, contact time and concentration of solution. Also noteworthy is the fact that uptake of metal ion depends upon the surface functional group of the adsorbent. For both of the adsorbents the maximum adsorption capacities are comparable with commercially available chelating resins and expected to be good candidate for adsorption of other metal ions in contaminated water stream.

\section{Acknowledgement}

Authors are highly grateful to the Head, Central Department of Chemistry, Tribhuvan University, Nepal for providing us the available research facilities to conduct this research. One of the authors Puspa Lal Homagai, gratefully acknowledges NAST for providing Ph.D. fellowship to undertake this study.

\section{References}

APHA.1998. Standard methods for the examination of water and wastewater. $20^{\text {th }}$ edition. American Public Health Association, Washington, DC.
Biswas, B.K., K. Inoue., K.N. Ghimire., H. Ohto and H. Kawakita.2007. Adsorption of phosphate from aquatic environment using metal-loaded orange waste. Journal of Colloid and Interface Science 312:214-223.

Dhakal, R.P., K.N. Ghimire and K. Inoue. $2005 \mathrm{a}$. Adsorptive separation of heavy metals from an aquatic environment using orange waste. Hydrometallurgy 79: 182-190.

Ghimire, K.N., K. Inoue., H. Yagamuchi., K. Makino and T. Mijayima.2003.Adsorptive separation of arsenate and arsenite anions from aqueous medium by using orange waste. Water Research 37: 4945-4953.

Ghimire, K.N., K. Inoue., K. Ohto and T. Hyasidha.2008. Adsorption study of metal ions onto crosslinked seaweed Laminaria japonica. Bioresource Technology 99: 32-37.

Mohan,D., K.P. Singh and V.K. Singh.2008. Wastewater treatment using low cost activated carbons derived from agricultural byproducts-A case study. Journal of Hazardous Materials 152(3): 1045-1053.

Pavas ant, P., R. A p iratiku l., V. S ungkhum ., P.Suthiparinyanot., S.Wattanachira and T.F. Murhaba, 2006. Biosorption of $\mathrm{Cu}^{2+}, \mathrm{Cd}^{2+}, \mathrm{Pb}^{2+}$ and $\mathrm{Zn}^{2+}$ using dried marine green macroalga Caulerpa lentillifera. Bioresource Technolology 97: 2321-2329.

Reddad, Z., C. Gerente., Y. Andres and P.L.Cloirec, 2002. Adsorption of several metal ions onto a low-cost biosorbent: Kinetic and Equilibrium studies. Environmental Science and Technology 36: 2067-2073. 
Nepal Journal of Science and Technology 10 (2009) 